\title{
Dynamics of internet Visibility: Mutual Benefits for Distinguished Alumni and Alma Mater?
}

Received (in revised form): September 28, 2004

\section{Dennis R. Ridley}

Dr. Ridley is the Director of Institutional Research and Planning at Virginia Wesleyan College, a four-year liberal arts college located in Norfolk, Virginia, USA. He earned a masters degree in educational research, as well as a Ph.D. in educational psychology from the University of California at Santa Barbara. Dr. Ridley is active and has published extensively in higher education research, assessment and evaluation, and institutional research.

\section{Alexei G. Matveev \\ Alexei G. Matveev is Associate Director of Institutional Effectiveness and Assessment at Norfolk State University and a doctoral candidate at the College of William and Mary. He holds an M.Ed from Kent State University in Educational Administration and an MA in Economic Sociology from Lancaster University in the UK.}

\section{Nuria M. Cuevas}

Nuria M. Cuevas is the Associate Vice President for Academic Affairs at Norfolk State University and Director of Institutional Effectiveness and Assessment at Norfolk State University in VA. Her areas of expertise include institutional effectiveness, assessment, and measurement and evaluation theory.

\begin{abstract}
Every college and university institutional advancement office would like to point to eminent alumni, living or deceased, as part of the institution's cultural legacy. However, little is known about the dynamics of how eminent alumni influence the reputations of their alma maters, particularly in the age of the internet. Has the internet created a new set of conditions that can level the
\end{abstract}

\footnotetext{
Author's Contact Address:

Dennis R. Ridley, Ph.D.

Director of Institutional Research and Planning

Virginia Wesleyan College

1584 Wesleyan Drive

Norfolk, Virginia 23502-5599

USA

Phone: +1 7574553401

Email: dridley@vwc.edu
}

playing field, providing new opportunities for younger institutions with few claims to eminent alumni? Or does the internet merely magnify advantages that older, well-established and endowed institutions already enjoy? This paper addresses this issue with new data on the internet visibility of institutions and their most eminent alumni, that is, US presidents.

\section{Keywords:}

alumni recognition, alumni bonors, cultural legacy, eminent alumni, institutional reputation, internet visibility

\section{Introduction}

Every college and university institutional advancement office would like to have more of a resource that is inherently rare-eminent alumni. Whether living or 
deceased, eminent alumni are part of the cultural legacy that the institution can showcase. But how much is known about the influence that distinguished alumni can have on the stature of an institution, including how to measure such influence? What are the parameters shaping that influence? It is a reasonable assumption that the association between distinguished alumni and their alma maters can have a positive and significant impact, in various ways rewarding the effort to publicize that association. At the same time, the lack of a relevant working theory, informed by credible evidence, makes it difficult to frame guides to practice that reach beyond common sense.

This paper is a first attempt to fill the need suggested above by summarizing some relevant research and discussing its possible implications. For this paper, the problem stated above first needed to be reframed in a way that accomplished two things: (1) mitigated the problem of how one can measure "influence," and (2) introduced a hugely important factor-the internet. The restated general issue is as follows: "What can be learned about the influence of eminent alumni on their alma maters as gauged by internet sources?" A related issue is, "What can an institution do to compensate for a relative lack of distinguished alumni?" Or stated another way, "Has the internet created a new set of conditions that can level the playing field, providing new opportunities for younger institutions with few claims to eminent alumni? Does the internet merely magnify advantages that older, well-established and endowed institutions already enjoy?"

The modern phenomenon of the internet provides a new and powerful way in which both institutions and individuals can achieve visibility throughout the world. Along with the internet are various ways that visibility within the internet world can be measured. A first study attempted to measure internet visibility as it pertains to colleges and universities by examining the frequency of appearance of the named institutions according to internet search engine hits. ${ }^{1}$ Public and private colleges and universities in Virginia were the objects of study. This operational measure of internet visibility revealed a huge gap separating the most and least visible institutions, that is, approximately a factor of 100 . The highest numbers were reported for large (predominantly public) research universities with extensive research and graduate education resources; the lowest numbers were for small private colleges primarily focused on undergraduate instruction.

A second study was based on a review of the literature that led to a conceptual model for understanding and measuring internet visibility of colleges and universities. ${ }^{2}$ The full model is discussed in the latter source. The present study focuses on one source of internet visibility identified in the model, that is, the "cultural capital" of the institution, of which eminent alumni and their association with institutions play a prominent part. The following questions were addressed: do eminent individuals contribute to the cultural capital of an institution in ways that can be measured? Does this contribution (and do its measurable effects) persist long after these eminent persons are deceased? Are such influences related to independent reliable measures of eminence in particular fields (e.g., political leadership exhibited by US presidents)?

If one could better understand what creates institutional visibility on the internet, in terms of cultural or other forms of capital, this information might 
contribute to the general ability both to understand and use the internet wisely, for example, in making use of the known and possibly measurable contribution of an eminent individual to an institution's reputation.

These reflections also raise the question of whether the cultural capital created by eminent individuals interacts differently with the internet as a function of the closeness of these individuals in time to the age of the internet. Even without the internet, one might imagine a compounding of influence over time, such that eminent individuals from an early period in our history created a legacy that has not faded but has persisted with the passage of time. Such compounding influence might appear in measures of internet visibility. On the other hand, internet visibility might be enhanced by the eminent individual's nearness to the present since more recent historical events are more relevant to modern websites and those who create and visit them. However, the question here is how much difference the internet has made in the visibility of the individuals in modern versus historical times. In other words, has the internet created special conditions that shape the visibility of eminent individuals in the present day, that is, those living during the age of the internet? Quite possibly, internet visibility might be magnified for those individuals whose careers corresponded most closely in time with the internet.

\section{Hypotheses}

Several tentative hypotheses guided this exploratory study. The first three concern relationships among internet visibility (of the eminent alumni), historical versus recent eras, and alumni (presidential) eminence.
- First, if eminence in a particular field can be measured reliably and validly, that measure will be positively correlated with alumni internet visibility.

- Second, it is suggested that time-related effects on internet visibility of alumni, independent of eminence, will be detectable during the period before the internet began to exert its influence, that is, among the historical or nonliving eminent alumni. However, the shape of those effects is unknown.

- Third, there appears to be an influence of the internet age upon internet visibility; that is, there will be a strong influence of recency within the internet age upon internet visibility.

The last two predictions concern the relationships among eminence and internet visibility of both the prominent alumni and their alma maters.

- Fourth, it will be possible to measure eminent individuals' contribution to the internet visibility of their alma maters.

- Finally, while the size of that contribution is unknown, it is suggested that it will be correlated with the eminence of the particular alumni.

\section{Rationale for Study Focus on Political Leadership}

Among alumni of US colleges and universities, US presidents occupy a high status in terms of historical and cultural significance. Of course, a different set of results might have surfaced had a different focus been chosen; on the other hand, this focus is useful because it examines a high level of ongoing influence (i.e., presidents) on the cultural capital of institutions, compared with other categories of eminent alumni that might have been examined. It is also 
interesting as a choice of study because the historical span is so longapproximately two centuries. This scope is long enough to allow us to examine timedependent effects such as those proposed above, while at the same time looking for possible effects of more recent conditions created by the presence of the internet during the lives of those being studied.

\section{Method}

\section{Internet visibility}

The methods used in this study were similar to those used in the first study mentioned above." "Internet visibility" of individuals and institutions is measured examining the frequency with which these entities are cited in the internet world, or the part of that world that is accessible. The means of measuring such visibility is readily found: internet search engines, which not only identify but count instances of word strings which correspond to the names of colleges and universities and eminent alumni. Thus, for the purpose of this article, "visibility" is defined as the number of hits generated through inputting the college's name into search engines, while controlling for false hits as much as possible. While other measures of internet presence also are worthy of study, ${ }^{4}$ this measure was adopted for exploratory purposes.

Since the internet is extremely dynamic and ever changing, it seemed important to capture the data at one moment in time. One problem with not doing so is that the numbers found, particularly for institutions, can vary enormously from one day to the next. Thus a particular date in 2002 was selected for gathering the data. The search engine used was Google. A previous study found a high degree of correspondence between results obtained using Google and Altavista. ${ }^{5}$ Therefore, for this exploratory study one search engine was deemed sufficient.

Like other search engines, Google offers several options. For example, the option "All Languages" was selected. In addition, there are various other options available, which may be studied by anyone who is interested by simply logging onto www.google.com and trying several examples. In general, the most literal option was used; that is, the exact string of words found in the most common version of the name or names being searched was used to match the searched web sites.

Care was taken to avoid ambiguity in order to control for false hits. As regards colleges and universities, the string to be inputted consisted of the formal name of the college or university. For the most part, this procedure was without ambiguity. However, the names of several colleges and universities raised the issue of ambiguity and inflated numbers. To care for these cases, the search excluded selected words to eliminate the ambiguity. Inspection of results suggested that this method was reasonably effective.

Similarly, care was exercised to reduce false hits for the names of presidents. In order to eliminate virtually all cases of mistaken identity, the president's name was preceded by the title, "President." This method of reducing false hits undoubtedly exacted some cost in missing some potentially valid hits; however, for this study the emphasis was placed on accuracy in the sense of controlling false hits.

Since there was some discretion regarding what name to enter for a president (e.g., "Ulysses S. Grant” vs "Ulysses Grant" or "Franklin D. Roosevelt" vs "Franklin Roosevelt" vs "Franklin Delano Roosevelt"), it was 
decided to use the option that maximized the number of hits, regardless of whether the middle name or initial was included.

Selective or "special hits" were also measured. They were intended to reveal when both the president and his alma mater were found together in the internet search. In practice, the method had some limitations for this purpose. A "special hit" starts with the specific search definition (as discussed above) for locating one of the two targets for counting hits, that is, eminent alumni or their alma maters. To these specific search definitions is added the requirement that the specific names for the other member of the pair must also appear in the webpage. This method was applied in two ways: starting with the president's name as the exact string required, or starting with the institution's name. The two methods produced results that were different, but correlated. Theoretically, given a perfect device, the same number representing the intersection of two items should be found twice. Evidently, the ambiguities in each individual search are even greater when looking for their intersection.

Despite these ambiguities, it is important wherever possible to seek validation through attempting to measure the same thing two or more ways. The two methods provide this point of validation. In addition, one "special hit" measure, starting with the search for the institutional name, was used in this paper as the basis for estimating the contribution of the president to the internet presence of the institution.

\section{Recency}

"Recency" of a president was defined in terms of the time since the year beginning the president's term of office.

\section{Eminence}

A convenient source for measuring "presidential eminence" was identified on a website created by C-Span to accompany its "American Presidents" series. ${ }^{6}$ The webpage states the following concerning the survey:

As the final element of our yearlong American Presidents series, C-SPAN conducted a Survey of Presidential Leadership, in which historians and viewers participated online. The survey rated 10 qualities of presidential leadership established by our advisory team, including each president's effectiveness within the context of our nation's changing expectations of the presidency. We sent the survey to the approximately 90 historians and presidential experts who've participated in our series.

The C-SPAN Survey of Presidential Leadership was crafted by a team of four historians and academics who have been deeply involved in the American Presidents series-Douglas Brinkley of the Eisenhower Center, Edna Greene Medford of Howard University, Richard Norton Smith of the Ford Library, and John Splaine of the University of Maryland.

In this study, only the summative scores and ranks of overall eminence (or "presidential leadership") were used. The ten qualities that were rated contributed to the overall scores. Those qualities included: public persuasion, moral authority, relations with Congress, crisis leadership, international relations, vision/ setting agenda, economic management, administrative skills, pursued equal justice for all, and performance within context of times.

Also, the nature of the study topic limited the selection of presidents to those 
who had attended and were graduated from a college or university. For that reason, some prominent presidents were absent in the data (e.g., George Washington, Abraham Lincoln, Harry Truman). In addition, the current president, George W. Bush, was not included in the C-Span study, which took place prior to his administration. Therefore, some of the comparisons of variables necessarily do not include Bush.

For this exploratory study, simple correlation coefficients were computed.

\section{Study Limitations}

The authors emphasize that the current study was carried out for exploratory purposes, that is, to cast a broad net to suggest and test hypotheses. The study's "conclusions," therefore, should be regarded as tentative and in need of further study in a more rigorous, verification mode.

Specific limitations to be noted relate to the use of correlation analysis with a small sample that probably is not normally distributed. While the sample size is fixed and cannot be enlarged beyond the number of college-educated presidents, the likely violation of assumptions underlying correlation analysis should be addressed in follow-up study by adopting different methods. Assumptions that should be examined in a future study include the normality of frequency distributions, levels of measurement of variables, linearity of variables, homogeneity of variance, and the possibility of spurious correlations. While these limitations should be borne in mind, again the intended purpose was exploration to stimulate informed thought on the issues raised above.

\section{Results and Discussion}

The results follow the order of the tentative hypotheses stated above. An archival source containing all of the data is available. ${ }^{7}$

First, if eminence in a particular field can be measured reliably and validly, that measure will be positively correlated with internet visibility.

Over all presidents (excluding the current president for the reason given above), there was a correlation coefficient of +0.13 found between eminence and internet visibility measured by search engine hits. This result was not statistically significant.

However, when a division was made between living (as of this writing) and nonliving presidents (Nixon and before vs Ford and later), the results were quite different. For nonliving presidents, a correlation coefficient of +0.57 was found between eminence and internet visibility; that is, greater eminence tends to go along with internet visibility. This result was significant beyond the 0.01 level of confidence. For the living presidents, on the other hand, the correlation coefficient of +0.01 was found, which of course was not significant.

Second, it is suggested that time-related effects on internet visibility, independent of eminence, will be detectable during the period before the internet began to exert its influence, that is, among the historical or nonliving eminent alumni. However, exactly what the shape of those effects might be was unknown.

The correlation between recency and search engine hits, over the nonliving presidents, was +0.57 , which was significant beyond the 0.01 level of confidence. When controlling statistically for the influence of eminence in the correlation (using a partial correlation), the partial correlation found was +0.71 , an 
even stronger and more significant result. In other words, search engine hits are positively affected by recency; the more recent the president, the greater the number of search engine hits. This association is statistically independent of the eminence of the presidents.

Third, it is suggested that there is an influence of the internet age upon internet visibility; that is, there will be a strong influence of recency within the internet age upon internet visibility.

When recency and search engine hits were correlated over all the presidents, a correlation coefficient of +0.55 was found, which was significant beyond the 0.01 level of confidence. However, when the division is made again between living and nonliving presidents, there is a clear difference in the results. As stated above, for nonliving presidents, the correlation coefficient was $+0.57(\mathrm{p}<0.01)$. For living presidents, the result was +0.97 , representing a nearly perfect positive linear relationship between recency and internet visibility, which was of course significant well beyond the 0.01 level of confidence.

There is a tremendous acceleration of the internet visibility measure during the administrations of living presidents (see Figure 1). The distribution of these values suggests that a Spearman rank correlation might be more appropriate than the Pearson correlation used earlier. This calculation yielded a new correlation of +0.94 , which is also significant beyond the 0.01 level of confidence.

Summarizing the above results, they suggest that eminence and recency both are associated with internet visibility. However, their joint influence appears to be different for the living and nonliving presidents. For the nonliving presidents, eminence and recency both have a modest level of association with internet presence (about +0.57 ); they are distinct and independent sources of association. For living presidents, eminence is completely invisible as a factor in internet visibility.

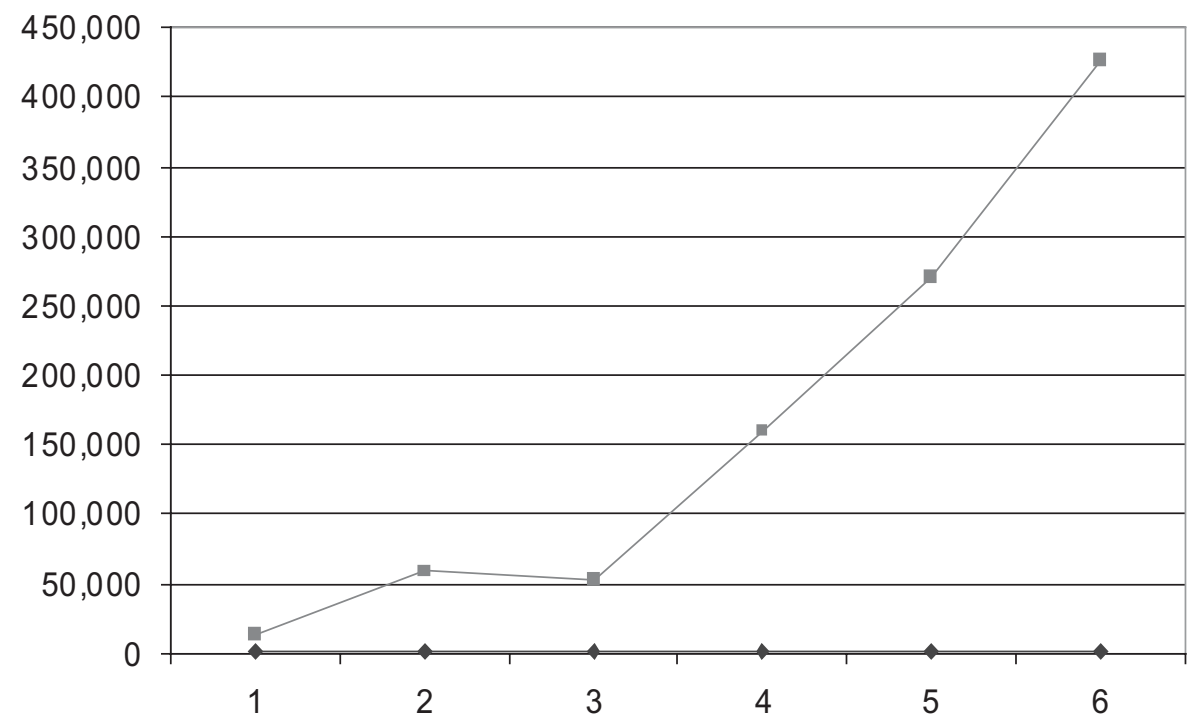

Figure 1: internet search engine hits on living US presidents in chronological order (1-6 = Ford, Carter, Reagan, G. Bush, Clinton, G.W. Bush) 
Recency appears to tell the whole story regarding internet presence in the internet age. The most recent presidents enjoy a huge advantage in internet presence that corresponds with the rapid growth of the internet itself.

Fourth, it will be possible to measure eminent individuals' contribution to the internet visibility of their alma maters.

In general, prior to the last several presidents, the number of hits on presidents was far less than the number of hits on their alma maters. This fact alone suggests that even presidents have, at best, a minor role on the internet presence of the institution they attended. Some presidents who attended small private colleges may be an exception. For example, Ronald Reagan showed far more internet hits than Eureka College, his alma mater. This observation might suggest that often there was a substantial contribution of the president to the college's internet presence. However, to make the case more strongly, other methods were used.

As explained in the method section, two "special hit" measures provided the basis to attempt to measure the eminent alumni's contribution to internet visibility of their alma maters. No attempt was made to apply these measures to currently living presidents, for the reason noted immediately above, that eminence apparently makes no detectable difference in internet presence during the age of the internet. However, for the nonliving presidents, these two measures correlated +0.82 , which is sufficiently high to provide validation, at least for the historical period of nonliving presidents. This result suggests that the two special hit measures, despite ambiguities, are strongly associated over these presidents and thus provide a reasonable estimate of the intersection of internet hits for presidents and their alma maters. For this exploratory study, only one "special hit" measure was used, that is, the one beginning with the internet hits on the alma mater, as explained above, and adding the president's name to "dial in" the intersection, that is, webpages containing both citations. This method provides the basis for addressing the fifth hypothesis below.

The exercise of creating these special variables leads us to conclude that they provide measures that are relevant to the issue identified above, that is, the contribution of eminent individuals to the internet visibility of their alma maters. These special variables do not directly measure such a contribution; however, as will be seen they provide the basis for an analysis suggesting that alumni eminence has a detectable role in the institution's internet presence.

Fifth, while not speculating as to size of the contribution, it is suggested that appearances of the alumnus name with the Institution will be correlated with the eminence of the particular alumnus.

The correlation coefficient, between the "special hit" measure mentioned above and eminence was only +0.34 (for nonliving presidents), which is marginally significant at best. However, the size of the special hit measure clearly depended on the internet presence of the institution. For example, Harvard University has a huge internet presence, far greater than that of the small private colleges attended by some of the presidents. Harvard's internet presence alone can account for a great deal of the large special hit measure for certain presidents, for example, the Roosevelts. At the same time, the Roosevelts were highly eminent presidents. The problem is to find a way to estimate how much of the high special hit measure can be attributed 
to presidential eminence and how much to the sheer size of the influence of Harvard. Thus, for a test of association to be sensitive to the contribution of eminent alumni, independent of the size of the alma mater and its internet presence, a special approach must be taken.

Toward that end, a partial correlation was calculated to determine the degree of association between the special hit measure for the alma mater and eminence, while controlling statistically for the size of the internet presence of the alma mater. The result was a correlation coefficient of +0.62 , which is significant beyond the 0.01 level of confidence. It is tentatively concluded that alumni eminence probably does make some difference, although more direct and sensitive tests of its influence would be desirable.

Summarizing the results from the above two issues, it is concluded that eminence, while not yet a significant factor in this internet age, appears to have a detectable role in the internet presence of colleges and universities that were the alma maters of nonliving presidents.

\section{Implications and Future Directions}

It is a fair question to ask what all of these provocative results might mean for modern colleges and universities, which would like to use the internet skillfully and intelligently. It is a truism that no college or university can rewrite its history to claim the ongoing cultural legacy of alumni who are not their own. However, the results suggest that in this internet age, new opportunities have been created, in some sense rewriting the rules of what makes an impact upon internet users. If such a conclusion holds up, it would offer hope to younger or less well- endowed colleges, since massive resources and institutional momentum might meet their match in an institution using its initiative, creativity, and imaginative flair to leverage positive benefits through its internet presence.

There is, of course, a controversy brewing over this very issue of whether the internet has, in a sense, leveled the playing field. There are two competing perspectives on the implications of the internet for institutional visibility. Optimists predict that the internet reduces inequality by lowering the cost of information and thus enhancing the ability of smaller and less wealthy institutions to gain visibility. ${ }^{8}$ Skeptics argue that the greatest benefits will accrue to wealthier institutions since they have used their resources to establish internet presence sooner and may penetrate the internet more productively, thus exacerbating existing inequality among higher education institutions.

However, some alternative suggestions come to mind. Arguably one major way in which the study suggests how the internet may have changed the rules is this: historical cultural legacy has its limits in the internet age. The reach of the internet back into the past also is limited. One finds a picture here that is reflective of much of our culture-impatient, on the move, having a finite attention span, and feeding insatiably upon current information. Thus, it is no cause for despair, but may even signal opportunity, when eminent people are hard to find on the alumni rolls. The college or university that highlights the accomplishments of its alumni may do itself a favor in the long run, if by so doing it can help them gain wider recognition including internet visibility. The principle here is that of bread cast upon the waters that returns to prosper the source. If an institution is 
privileged to have nurtured a president, that may be all to the good-but the institution would be advised to recognize the limitations of even that association. Let us suppose the president or other eminent alumnus or alumna is a source of unalloyed pride (which is not always the case). Even then, that permanent association may lose its luster and have limited "information highway/street value," since part of the genius of the internet is to continually reflect and feed upon the boiling, constantly shifting variety of modern society.

An institution might be well advised to follow the example of the University of North Carolina, which in an affiliated website acknowledged James K. Polk as its most prominent alumnus (after over 150 years), then quickly went on to acknowledge many others:

Alumni of the University include US President James K. Polk, author Thomas Wolfe, journalist Charles Kuralt, former White House Chief of Staff Erskine Bowles, corporate banker Hugh McColl, journalist Roger Mudd, actor Andy Griffith, designer Alexander Julian, actor Sharon Lawrence, sportscaster Stuart Scott, basketball greats Michael Jordan and Vince Carter, World Cup and Olympic soccer player Mia Hamm, and track standout Marion Jones. $^{10}$

Whoever the prominent alumni might be, it can never hurt to bring them out for display and promote them on the internet. Indeed, it could be argued that there will be more reciprocal gain in promoting relatively less well-known alumni than those who already have huge reputations or have been dead for over a century.

Virginia Wesleyan College also used a similar approach in recognizing one of its most distinguished alumni with an Honorary Doctorate of Science degree. ${ }^{11}$ The alumnus was recognized for outstanding business success in the pharmaceutical industry and for noteworthy community service. This individual, although a member of an early graduating class at Virginia Wesleyan, is far from finished with his career. He is currently involved with starting (at last count) two new pharmaceutical companies. This alumnus's star clearly is still on the rise. The honoree described the award as "an incredible honor." It is arguably a boost to his stature, and thus represents (as suggested above) an investment, which sooner or later likely will redound to the benefit of the institution. Such an outcome appears more likely at a small, less established institution, as the example of Ronald Reagan and his alma mater Eureka College suggests.

This exploration, or any single study, cannot begin to resolve the many issues that the subject of institutional internet visibility raises. However, the study provides one more brick in the ongoing effort to construct a better understanding of the internet and its impacts. Every institution must make adjustments to the internet quickly; it is changing much too rapidly to permit us the luxury of desultory and tentative applications. We cannot wait for all the data to come in. Nonetheless, we need to balance the need for action with the effort required to assess which endeavors will lead to the greatest payoffs. This paper offers a contribution toward that goal.

\section{References}

1. D. R. Ridley (2002), "Internet visibility measured by search engine hits: A test on Virginia colleges and universities," Resources in Education, ERIC 
Clearinghouse on Higher Education, ERIC Document number ED 461351.

2. A. G. Matveev, D. R. Ridley, and N. M. Cuevas (2002), "Becoming web smart: An exploratory study of internet visibility of Virginia's college and university websites," online publication sponsored by the Virginia Assessment Group and Virginia Association for Management Analysis and Planning Virtual Conference 2002, archive located at <http:// www.brcc.edu/research/vagvamap2002.html>.

3. Ridley (2000), "Internet visibility measured by search engine hits," op. cit.

4. Matveev et al. (2002), "Becoming web smart," op. cit.

5. Ridley (2002), "Internet visibility measured by search engine hits," op. cit.

6. American Presidents Life Portraits: A Site to Complement C-SPAN's 20th Anniversary Television Series, American Presidents: Life Portraits, MarchDecember 1999. (2000) <http:// www.americanpresidents.org/survey>.

7. D. R. Ridley, A. G. Matveev, and N. M. Cuevas (2003), "Exploring internet visibility of eminent alumni: Variables and correlates," Resources in Education, ERIC Document Number ED 468119.
8. M. Hauben and R. Hauben (1997), Netizens: On the History and Impact of Usenet and the internet. IEEE Computer Society Press, Los Alamitos, CA.

9. P. DiMaggio and E. Hargittai (2001), "From the 'digital divide' to digital inequality: Studying internet use as penetration increases," Working Paper, Center for Arts and Cultural Policy, Princeton University. Retrieved from <http:// www.webuse.umd.edu/webshop/resources/ Dimaggio_Digital_Divide.pdf $>$, April 15, 2002; M. L. Klassen (2002), "Relationship marketing on the internet: The case of top- and lower-ranked US universities and colleges," Journal of Retailing and Consumer Services, 9, 81-5; M. L. Klassen and E. Sitzman (2000), "At the intersection of demand creation and demand fulfillment: Which schools are getting there first and why?" Journal of Marketing for Higher Education, 10, 1, 43-53.

10. Orange County, North Carolina Economic Development Commission, University of North Carolina Chapel Hill webpage <http:// www.co.orange.nc.us/ecodev/unc/>.

11. C. Douglass (2003), "Alumnus presented with honorary doctorate degree," Marlin Chronicle Online, May 2, 2003, <http://student.vwc.edu/ chronicle/ 5_2_03/news2.htm>.

\section{Practitioner's Perspective}

Every development office in higher education searches constantly for ways to elevate the positive visibility and perceived stature of its institution-especially among potential donors. At the same time, those same development offices are working diligently to cultivate their alumni and prominent supporters for both annual and major gifts.

Dr. Ridley's provocative study suggests that these two activities, far from being independent, actually could be synergistic-especially in this "Internet Age." While not every college or university can expect to claim a US President as an alumnus, the conclusion that alumni eminence "has a detectable role in the institution's internet presence," suggests that all institutions would be well-served to identify their own "eminent alumni."

While most "eminent alumni" are already well known to their alma maters, one practical step is to conduct an analysis similar to Dr. Ridley's to rank order the importance of such alumni.

The next step which should be considered is to boost the stature of even the most prominent of these "eminent alumni" by featuring them and their accomplishments on the institution's own website, and in any internet communications used by the institution. This two-step approach sets up the very real possibility of a symbiotic interaction whereby the publicity accorded the alumni heightens their "eminence," and that "eminence" in turn, enhances the perceived reputation of the institution. This approach has the additional advantage of paying public recognition to alumni whose support of the institution is critical and deeply appreciated. That such recognition can be paid immediately and broadly via the internet can also be beneficial to both alumnus and the institution. 
Incorporating lists of prominent alumni into the institution's "permanent" website, as the University of North Carolina has done, should be considered a minimal requirement for alumni relations. Likewise, regular email communications to alumni and other supporters should feature an "Alumni Spotlight," which can recognize the contributions-financial and other-of valued alumni, and this will serve to enhance "eminence quotient" of those alumni, which will, in turn, boost the recognition of the institution.

This application of "internet dynamics" can potentially result in escalating symbiosis; in any event, it certainly is a "no-lose" proposition.

John M. Cranor, III

President and CEO New College Foundation, Inc., New College of Florida 